\title{
RESISTÊNCIA DO SOLO À PENETRAÇÃO E DESENVOLVIMENTO RADICULAR DA SOJA SOB SISTEMA PLANTIO DIRETO COM TRÁFEGO CONTROLADO DE MÁQUINAS AGRÍCOLAS
}

\author{
Soil penetration resistance and soybean root growth under no till with controlled traffic farming
}

\begin{abstract}
Vitor Cauduro Girardello ${ }^{1 *}$; Telmo Jorge Carneiro Amado²; Antônio Luis Santi ${ }^{3}$, Mastrângelo Enivar Lanzanova ${ }^{4}$, Alto Tasca ${ }^{5}$

\footnotetext{
${ }^{1}$ Professor; Departamento de Ciências Agrarias; Universidade Reginonal Integrada do Alto Uruguai e das Missões - URI campus Santo Ângelo; vitorgirardello@santoangelo.uri.br (*AUTOR PARA CORRESPONDÊNCIA)

${ }^{2}$ Professor; Departamento de Solos; Universidade Federal de Santa Maria; florestatel@ hotmail.com.br

3 Professor; Universidade Federal de Santa Maria, Departamento de Ciências Agronômicas e Ambientais, Frederico Westphalen, RS, Brasil. Email:santi_pratica@yahoo.com.br

4Professor; Universidade Estadual do Rio Grande do Sul, Unidade Três Passos, RS, Brasil. Email: mastrangello-

lanzanova@uergs.edu.br

${ }^{5}$ Engenheiro Agrônomo responsável técnico da empresa AgroTasca, Céu Azul, PR, Brasil, Email: aldo_tasca@hotmail.com
}

Artigo enviado em 16/02/2017, aceito em 19/04/2017 e publicado em 07/07/2017.

\begin{abstract}
RESUMO - Organizar o tráfego de máquinas agrícolas que atualmente ocorre de maneira aleatória dentro das áreas comerciais é uma ação com efeito de mitigar os problemas de compactação. Uma vez que o tráfego de máquinas de grande porte sob condições inadequadas de umidade (elevada umidade) do solo, associada com a inadequada rotação de culturas e baixo aporte de massa seca, acaba induzindo a ocorrência da compactação do solo. O controle do tráfego de máquinas agrícolas (tráfego controlado) é uma opção para mitigar as perdas de produtividade das culturas associadas a compactação do solo. Este estudo foi conduzido com o objetivo de avaliar as modificações impostas pelo tráfego controlado de máquinas na resistência do solo a penetração, no desenvolvimento do sistema radicular e na produtividade da soja. O solo do local é classificado como Latossolo Vermelho com textura muito argilosa. Os tratamentos investigados foram: (a) Sem tráfego de máquinas (tratamento de referência) (ST); (b) Tráfego restrito a passagem do conjunto trator-semeadora (TT); e (c) Tráfego máximo acumulando passagens de pulverizador e do conjunto trator-semeadora (TM). O delineamento experimental foi o de blocos inteiramente casualizados, com 3 blocos e 5 repetições. A implantação parcial do sistema de tráfego controlado aumentou a resistência do solo a penetração em locais onde ocorreu o tráfego das máquinas, porém não alcançando valores críticos. O sistema radicular da soja apresentou maior comprimento na camada entre $0,10-0,30 \mathrm{~m}$ no tratamento ST, que apresentou produtividade de grãos 7\% maior que o tratamento TM, sem apresentar diferença estatística entre eles.
\end{abstract}

Palavras-chave - agricultura de precisão, compactação do solo, penetrometria.

\begin{abstract}
Controlled traffic farming (CTF) is an efficient tool to mitigate the negative impact of soil compaction in croplands. Since, the traffic of heavy machinery under high soil moisture associate to lack of soil disturbance under no-till, mainly in crop systems with absence of crop rotation result in soil compaction. As alternative to soil management emerge CTF with potential to avoid yield loss by soil compaction and increase machinery efficiency. The objective of this study was to evaluate the changes imposed by CTF in soil penetration resistance and soybean root growth and grain yeld. The soil is classified as an Oxisol and the climate is cfa in Koeppen classification. The treatments investigated were: (a) No traffic, the reference treatment (NT); (b) Planter and tractor traffic (TT) and (c) Maximum Traffic, accumulating sprayer and tractor-planter (MT). The design experimental was a randomized block with 3 blocks and 5 replicates. In this study, a partial CTF was implanted where the traffic caused an increase in soil penetration resistance but the critical values to this parameter was not reached. The ST treatment had a higher soybean root growth in the $0.10-0.30 \mathrm{~m}$ soil layer and a grain yield increase of $7 \%$ in relation to the MT, without stastical difference.
\end{abstract}

Keywords - precision agriculture, soil compaction, penetrometrer. 


\section{INTRODUÇÃO}

Atualmente, os gestores de sistemas agrícolas têm sido desafiados a intensificar os cultivos, incrementar a produtividade das culturas e a eficiência dos recursos utilizados. Neste contexto, o incremento do trânsito de máquinas agrícolas, o aumento do tamanho e peso destas máquinas, associado ao reduzido tempo para execução das atividades tem ocasionado que, geralmente, as operações sejam executadas sem respeitar as condições de umidade do solo ideiais, resultando em compactação do solo (TREIN et al., 2009).

Atualmente, a compactação do solo é considerada o principal desafio a ser enfrentado em áreas mecanizadas manejadas sob sistema plantio direto que visam elevadas produtividades (STEFANOSKI, et al., 2013). A compactação tem como consequências o decréscimo de produtividade, aumento da resistência a penetração do solo que ocasiona a redução no desenvolvimento radicular das plantas (CHAN et al., 2006, CHEN e WEIL, 2010)

Eliminar completamente o tráfego de máquinas nos sistemas agrícolas comercial é inviável, porém alternativamente $\mathrm{o}$ número, a intensidade $\mathrm{e}$ a aleatoriedade do tráfego podem ser reduzidos, bem como as manobras nas extremidades da área. Com o uso de ferramentas da agricultura de precisão com destaque ao sistema de piloto automático e a base RTK (Real Time Kinematic), é possível a implantação do sistema de trafego controlado em larga escala (BOCHTIS et al., 2010).

O tráfego controlado basea-se no planejamento do trânsito de todas as máquinas e equipamentos envolvidos no processo produtivo, fazendo com que haja coincidência do rastro dos rodados, confinando a compactação a locais específicos denominados de linhas de tráfego (CHAMEN et al., 2003; TULLBERG et al., 2007).

O sistema de tráfego controlado em culturas de grãos ainda é incipiente no sul do Brasil, sendo as principais dificuldades para a sua adoção em larga escala: o correto dimensionamento das máquinas agrícolas, a ocorrência de relevo suave ondulado que implica em operar máquinas agrícolas em curvas e a ausência de informações sobre o retorno econômico desta prática (GASSEN et al., 2011).

Entre as principais adaptações necessárias destacam-se os ajustes das bitolas dos rodados para que haja coincidência, e a necessidade de estabelecer um módulo de largura da barra de aplicação dos pulverizadores, número e distância entre linhas nas semeadoras e largura da plataforma de corte da colhedora. O ajuste na bitola dos pneus traseiros, definida como a distância entre o centro do pneu até o centro do pneu do lado oposto, é o processo de maior complexidade, sendo porém esta intervenção essencial para a implementação do sistema proposto (KROULÍK et al., 2010).

A semeadura e a colheita também devem receber atenção no processo, pois o espaçamento e o número de linhas devem ser iguais ou múltiplos da largura da plataforma de colheita (ALBA et al., 2011). O pulverizador é a máquina que apresenta maior flexibilidade neste ajuste, uma vez que as alterações são realizadas diretamente no comprimento da barra de pulverização. A linha de tráfego do pulverizador é utilizada como balizadora da linha de trânsito ("tramline") na qual todas as demais máquinas devem trafegar (BOCHTIS et al., 2010). Embora tecnicamente viável, a adoção do tráfego controlado tem sido reduzida em parte pela falta de informações sobre o desempenho das culturas econômicas.

O objetivo deste trabalho foi avaliar a resistência à penetração do solo, o comprimento do sistema radicular e a produtividade da soja em área comercial manejada sob sistema plantio direto com sistema parcial de tráfego controlado de máquinas agrícolas no Sul do Brasil.

\section{MATERIAL E MÉTODOS}

$\mathrm{O}$ experimento foi conduzido em área agrícola localizada no município de Céu Azul, região centrooeste do estado do Paraná. O talhão escolhido possuía $18,7 \mathrm{ha}$, situado sob as coordenadas geográficas $-25^{\circ} 6^{\prime}$ 52.12" S e $-53^{\circ} 50^{\prime} 22.61^{\prime \prime} \mathrm{O}$, seguindo o Datum WGS 84, e altitude de $633 \mathrm{~m}$ acima do nível do mar (Figura 1). A precipitação média anual varia entre 1.100 até 1.500 $\mathrm{mm}$, regularmente distribuída entre os meses do ano.

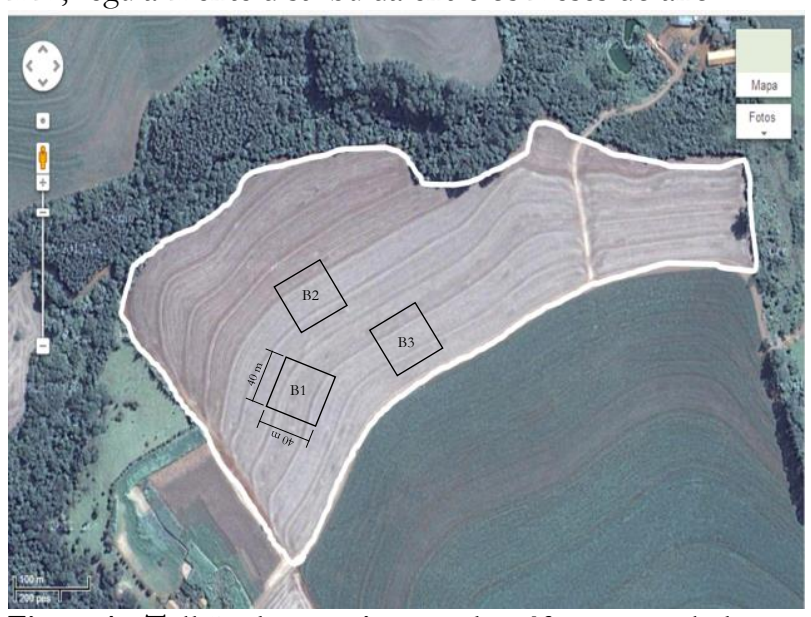

Figura 1 - Talhão do experimento de tráfego controlado, em destaque o posicionamento dos blocos. Municipio de Céu Azul, PR. Imagem obtida do Google.

O clima é subtropical, tipo $\mathrm{Cfb}$, segundo a classificação de Köppen. O solo é classificado como Latossolo Vermelho, com textura muito argilosa (EMBRAPA, 2013). 
A camada de 0,0-0,20 $\mathrm{m}$ de profundidade apresentou os seguintes atributos: teores de argila, silte e areia com 760, 150 e $90 \mathrm{~g} \mathrm{~kg}^{-1}$ respectivamente, $\mathrm{pH}$ em água $=5,0$ e saturação por bases $(\mathrm{V})=59,1 \%$. As concentrações de P (Mehlich-1) e $\mathrm{K}^{+}$no solo foram de 13,2 e 148,5 $\mathrm{mg} \mathrm{dm}^{-3}$, respectivamente. Ainda, os teores de $\mathrm{Ca}^{2+} ; \mathrm{Mg}^{2+} ; \mathrm{Al}^{3+}$ e $\mathrm{H}^{+}+\mathrm{Al}^{3+}$ apresentaram os seguintes valores: 5,$6 ; 1,7 ; 0,0$ e $5,3 \mathrm{cmol}_{\mathrm{c}} \mathrm{dm}^{-3}$, respectivamente.

O delineamento experimental utilizado foi o de blocos inteiramente casualizados, com três blocos (40 x $40 \mathrm{~m}$ ) e cinco repetições em cada bloco totalizando uma área experimental de $4.800 \mathrm{~m}^{2}$ (Figura 1). As avaliações foram divididas em duas épocas, sendo a primeira logo após a semeadura da soja, em meados do mês de outubro de 2013, e a segunda no pleno florescimento da cultura, no mês de janeiro de 2014.

Os tratamentos investigados foram: (a) Sem tráfego (tratamento de referência) (ST); (b) Tráfego restrito a passagem do conjunto trator-semeadora (TT); e (c) Tráfego acumulando passagens de pulverizador e do conjunto trator-semeadora (TM). As determinações realizadas foram: resistência do solo à penetração (RP), comprimento do sistema radicular em diferentes camadas de solo, e produtividade de grãos da soja.

Para a determinação da RP foi utilizado um penetrômetro PNT-2000, com ponta cônica de $30^{\circ}$ e com área do cone de $129 \mathrm{~mm}^{2}$. As leituras foram realizadas a cada $0,01 \mathrm{~m}$ até uma profundidade máxima de $0,40 \mathrm{~m}$, com 10 repetições em cada tratamento, na linha central do tráfego das máquinas. Na segunda época as determinações foram feitas apartir do centro da linha de tráfego e a cada $0,20 \mathrm{~m}$, de forma a formar um transecto de RP em cada tratamento. Simultaneamente, foram coletadas amostras de solo para a determinação da umidade gravimétrica do solo nas camadas de $0-0,1$ e $0,1-0,3 \mathrm{~m}$.

A determinação do comprimento do sistema radicular da cultura da soja foi realizada 102 dias após a semeadura, no pleno florescimento (FEHR et al. 1971), através de imagens digitalizadas, sendo realizadas três repetições em cada tratamento. Para isso abriu-se manualmente trincheiras no solo com tamanho de 1,00 $\mathrm{m}$ de largura por $0,50 \mathrm{~m}$ de profundidade, perpendiculares à linha de semeadura e com distância de $0,03 \mathrm{~m}$ do colmo da planta. Em um primeiro momento procedeu-se a limpeza manual da parede da trincheira para a exposição do sistema radicular da cultura.
Após a preparação da trincheira, introduziu-se no solo uma estrutura de madeira dividida em quadrículas de 0,10 x 0,10 m delineadas por fio de nylon preto ( $3 \mathrm{~mm}$ de diâmetro) formando referências para posterior pós processamento digital. Este processo foi realizado com o programa Corel Draw 12 para se obter o contraste necessário na utilização do programa SIARCS 3.0® (Sistema Integrado para Análises de Raízes e Cobertura do Solo) proposto por Crestana (1994) para a avaliação do sistema radicular.

A determinação do sistema radicular e da produtividade da cultura foi realizada nas plantas que se encontravam adjacentes as linhas de tráfego, uma vez que no local do trânsito de máquinas não existia a presença das plantas. Por outro lado, as avaliações de RP foram determinadas exatamente no centro da linha onde ocorreu o tráfego das máquinas. No tratamento com ausência de tráfego, as determinações foram realizadas na entrelinha da cultura em área livre de trânsito de máquinas.

A produtividade da soja foi determinada através de colheita manual em cinco repetições em cada bloco. Nestes locais foram colhidos $1 \mathrm{~m}^{2}$ da cultura, e em laboratório procedeu-se a debulha manual, posteriormente ajustando os resultados para 13\% de umidade. A colheita foi realizada no final do mês de fevereiro de 2014.

Histórico de manejo da área e descrição das máquinas utilizadas

A instalação do sistema de tráfego controlado iniciou de maneira parcial no ano de 2010. Em um primeiro momento fez-se as modificações para o manejo da cultura comercial, que na propriedade são as culturas de verão. A principal alteração ocorreu no espaçamento entre linhas da semeadora, que antes eram de 0,50 e após passou a ser utilizado o espaçamento de $0,70 \mathrm{~m}$ ( na soja), possibilitando assim a coincidência de linhas com a cultura do milho, seguindo o proposto por Gassen (2011), que as primeiras intervenções de manejo, ajuste de bitolas, de espaçamento de linhas de semeadora, largura de trabalho dos pulverizadores, devem ser realizadas na cultura com maior retorno econômico e somente após, partir para as adaptações nas demais culturas (Tabela 1). 


\author{
REVISTA SCIENTIA AGRARIA \\ Versão On-line ISSN 1983-2443 \\ Versão Impressa ISSN 1519-1125 \\ SA vol. 18 n .2 Curitiba Abr/Jun. 2017 p. 01-10
}

Tabela 1 - Histórico de manejo a as principais alteraçãos realizadas para implementação do sistema de tráfego controlado de máquinas.

\begin{tabular}{|c|c|c|c|c|c|}
\hline \multirow[t]{2}{*}{ Operações } & \multicolumn{5}{|c|}{ Ano agrícola } \\
\hline & $2011 / 12$ & 2012 & $2012 / 13$ & 2013 & $2013 / 14$ \\
\hline Cultura & Soja & Aveia & Milho & Aveia & Soja \\
\hline Adubação $\left(\mathrm{kg} \mathrm{ha}^{-1}\right)$ & $\begin{array}{c}60(\mathrm{KCl}) \\
250(\mathrm{SFS}) \\
25(\mathrm{~S})\end{array}$ & $\begin{array}{l}120(10-15-15) \\
1600 \text { (Calcário) }\end{array}$ & $\begin{array}{c}75(\mathrm{KCl}) \\
500(10-15-15) \\
140(\mathrm{~N})\end{array}$ & $\begin{array}{c}60 \text { (KCl) } \\
120 \text { (MAP) } \\
100 \text { (Calcário) } \\
2000 \text { (Gesso) }\end{array}$ & $\begin{array}{c}100(8-40-00) \\
80(\mathrm{KCl})\end{array}$ \\
\hline Número de plantas & $12 \mathrm{pls} / \mathrm{m}$ & $75 \mathrm{~kg} \mathrm{ha}^{-1}$ & $4 \mathrm{pls} / \mathrm{m}$ & $75 \mathrm{~kg} \mathrm{ha}^{-1}$ & $14 \mathrm{pls} / \mathrm{m}$ \\
\hline Data de semeadura & $18 / 10 / 2013$ & $19 / 04 / 2012$ & $13 / 10 / 2013$ & $20 / 04 / 2013$ & $10 / 10 / 2013$ \\
\hline Produtividade (kg ha-1) & 3,300 & $\mathrm{NC}$ & 13,620 & $\mathrm{NC}$ & 4,015 \\
\hline Espaçamento* (m) & 0,70 & 0,17 & 0,70 & 0,17 & 0,70 \\
\hline Largura da semeadura & 6,3 & 3,5 & 6,3 & 3,5 & 6,3 \\
\hline Passe trator** & 1 & 0 & 1 & 0 & 1 \\
\hline Passe pulverizador** & 7 & 4 & 7 & 7 & 5 \\
\hline
\end{tabular}

O trator utilizado foi um Case Magnum $220^{\circledR}$, com motor de $161 \mathrm{~kW}(220 \mathrm{cv})$ e peso de embarque de $12.750 \mathrm{~kg}$, equipado com rodados duplos, com pneus dianteiros de bitola 20.8-38 com 0,50 m de largura e com pressão de insuflação de $124 \mathrm{kPa}$; e pneus traseiro duplos 19.5-24 com 0,45 m de largura, usando pressão de insuflação de $165 \mathrm{kPa}$. A bitola dos pneus internos traseiros e dos pneus dianteiros são de $1,90 \mathrm{~m}$. O pneu externo traseiro possui bitola de 3,20 m.

Foi utilizado o sistema de piloto automático, AFS Guide ${ }^{\circledR}$, atuando diretamente no sistema hidráulico. O sinal de correção possui uma estação Base RTK Topcon HiPer AG $^{\circledR}$ (base fixa) que envia um sinal de rádio UHF para um módulo de rádio acoplado ao receptor GNSS AGI- $3^{\circledR}$, possibilitando trabalhar na maior parte do tempo com um erro inferior a $0,025 \mathrm{~m}$.

O pulverizador utilizado foi o modelo Gladiador $2300^{\circledR}$, Stara, com motor de $100 \mathrm{~kW}(135$ $\mathrm{cv})$ e peso total de embarque de $7.200 \mathrm{~kg}$. Os pneus utilizados são do modelo 12.4-36 com insuflação de $380 \mathrm{kPa}$, largura de $0,30 \mathrm{~m}$ e bitola de $2,80 \mathrm{~m}$. A barra de aplicação possui desligamento de sessão a cada 0,50 m. A semeadura das culturas de verão (soja e milho) foram realizadas com a semeadora Victoria Control
5400 (Stara), com peso total de $6.600 \mathrm{~kg}$. Nas operações de semeadura utilizou-se elementos de abertura de sulco para a deposição de fertilizantes tipo haste (sulcador) com profundidade de atuação variando entre $0,15-0,20 \mathrm{~m}$.

Diferentemente do modelo tradicionalmente utilizado pelos produtores, o pulverizador neste estudo atuou no mesmo sentido de semeadura na cultura da soja, fato possibilitado pelo espaçamento entre-linhas da cultura (Figura 2). Possibilitando uma configuração de tráfego que em cada quatro passadas de semeadora, ocorra a coincidência com uma passada do pulverizador, formando nesta linha de tráfego a área com o máximo de trânsito dentro da lavoura. Neste caso o produtor desconsidera uma pequena diferença de $0,02 \mathrm{~m}$ entre as passadas da semeadora e a cobertura total do pulverizador.

Os dados coletados foram submetidos à análise de variância, com uso do programa computacional ASSISTAT 7.6 beta (SILVA e AZEVEDO, 2009) sendo as médias comparadas pelo teste de Tukey em nível de $5 \%$ de probabilidade de erro. Os dados apresentaram distribuição normal e homogeneidade das variâncias. 


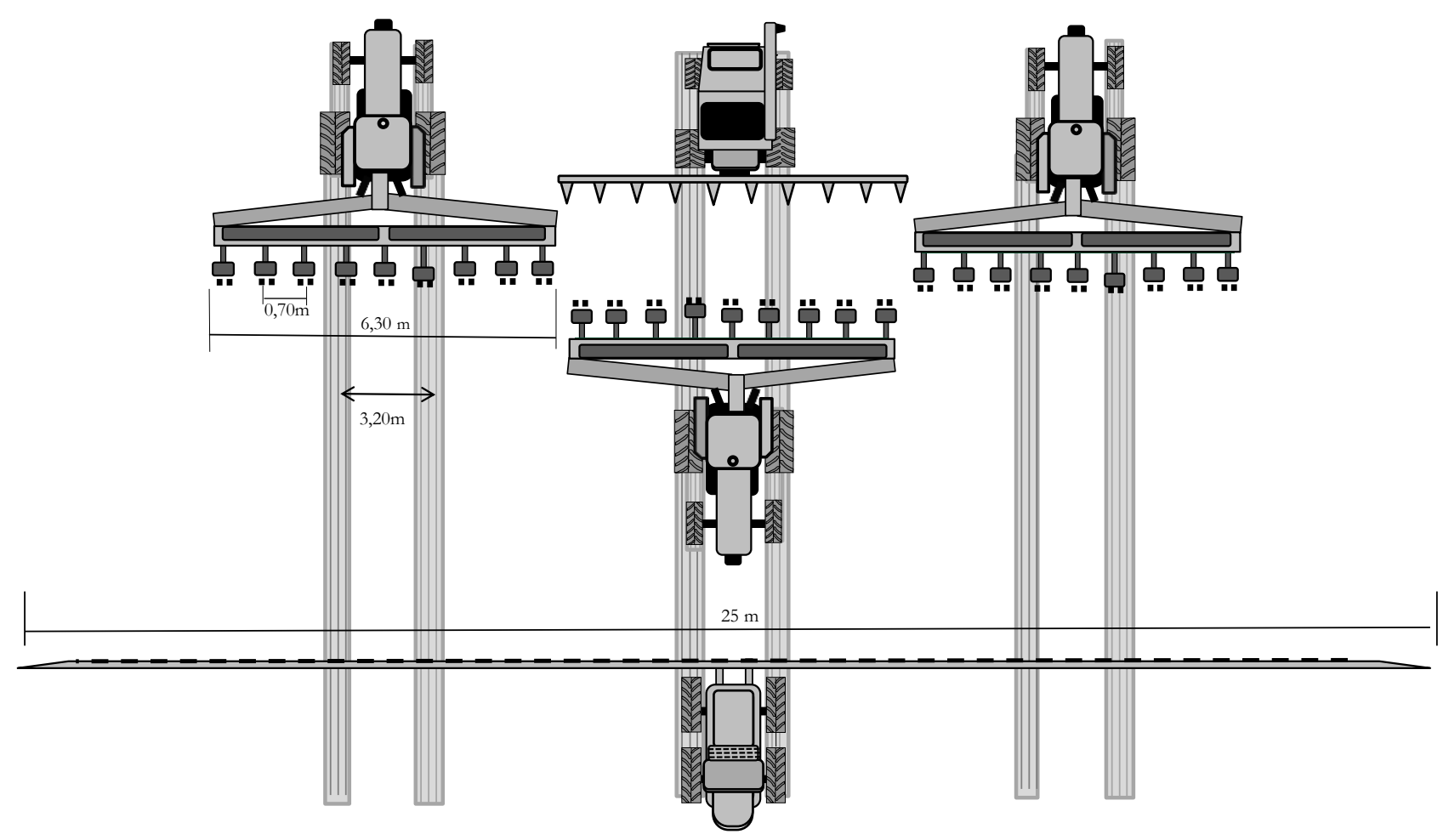

Figura 2 - Representação simplificada do sistema de tráfego controlado executado de maneira parcial no talhão experimental. Adaptado de Alba et al., 2011.

\section{RESULTADOS E DISCUSSÃO}

\section{Resistência à Penetração do Solo}

Transcorridos três anos após a implantação do sistema de tráfego controlado, durante o ciclo da soja foi realizada a primeira determinação da RP, imediatamente após a semeadura (Figura 3 A). A maior RP foi registrada no tratamento TT com o valor máximo na profundidade de $0,12 \mathrm{~m}$, atingindo $1,75 \mathrm{MPa}$, sendo $65 \%$ maior que o tratamento ST na mesma profundidade. A RP determinada foi classificada como moderada (Arshad et al.,1996), não atingido o limite crítico $(>2 \mathrm{MPa})$ proposto por Tormena et al. (1998). O TT na média geral da canada 00-0,40 m, apresentou incrementos de 24,5 e $23,5 \%$ na RP em relação aos tratamentos TM e ST, respectivamente.

Ainda, foi possível observar que durante o período de avaliação, o tratamento T'T apresentou aumento significativo da RP até a profundidade de $0,35 \mathrm{~m}$ ( Figura $3 \mathrm{~A}$ ) em relação ao TM e ST. Neste período do desenvolvimento da cultura, fase de emergência e desenvolvimento inicial, a presença de camadas mais compactadas superficialmente, prejudica o estabelecimento da cultura, uma vez que a emergência e o crescimento radicular estão relacionadas às restrições físicas impostas pelo solo.
Porém, os efeitos da compactação sobre o crescimento radicular e sobre a produtividade de grãos serão influenciados pelo tempo em que as plantas serão submetidas a esse estresse (BENGOUGH et al., 2006).

A compactação do solo em caso de excesso de precipitação na fase vegetativa de desenvolvimento da cultura pode induzir menor crescimento das plantas, devido à falta de oxigênio (ETANA et al., 2013). Por outro lado, na ocorrência de limitada precipitação, com o aumento da RP, ocorre redução da infiltração e armazenamento de água (TORMENA et al., 2007), o que pode induzir decréscimo da produtividade déficit hídrico mesmo sob déficit hídrico de curta duração.

No pleno florescimento da cultura da soja (FERH et al., 1997) foi realizada a segunda avaliação da RP (Figura 3 B). O comportamento desta determinação quanto a RP máxima foi semelhante a avaliação anterior, não atingindo a RP limitante ao desenvolvimento do sistema radicular e sendo classificada, segundo Arshad et al. (1996), como moderada. Destaca-se ainda, que o sistema plantio direto, com constante aporte de material vegetal através da rotação de culturas, pode contribuir para uma maior capacidade de suporte frente as 
modificações imposta de tráfego de máquinas (MAZURANA et al., 2013).

De um modo geral, neste estudo houve um decréscimo da RP na avaliação do florescimento em relação a avaliação realizada quando da implantação da cultura. Quando se compara as diferentes épocas de avaliação, ocorreu uma redução na RP média de 30; 8 e 4\% nos tratamentos ST, TT e TM, respectivamente. Assim, quanto menor a intensidade de tráfego maior foi a recuperação temporal da estrutura do solo. Este efeito pode ser atribuído ao sistema radicular da cultura da soja e atividade da mesofauna do solo. Como a compactação não foi limitante ao crescimento radicular e ocorreu na camada superficial na qual se concentrava o sistema radicular sua reversão foi possível. Porém, o decréscimo na RP foi maior no tratamento livre do tráfego. Estes resultados podem ser explicados em parte pelo sistema de manejo utilizado na área, em que o constante aporte de cobertura vegetal, e a presença de sistema radicular de culturas diferentes (aveia, soja, milho), condicionam a atividade biológica que contribui para a melhoria na estrutura do solo (McHUG et al., 2009). Assim, o tráfego controlado pode contribuir para aprimorar a qualidade do Sistema plantio direto por potencializar os efeitos biológicos na melhoria da estrutura (TULLBERG et al. 2007; QINGJIE et al.,2009).

No florescimento, o tratamento T'T apresentou a maior RP, com um incremento em relação ao tratamento ST de $80 \%$ a partir da profundidade de $0,20 \mathrm{~m}$. Na camada total avaliada (00-0,40 m), o tratamento TM apresentou o maior valor médio de RP entre os tratamentos investigados, sendo $42 \%$ superior ao tratamento ST. O maior decréscimo da RP induzida pela cultura da soja ocorreu nos primeiros $0,20 \mathrm{~m}$. Nesta segunda avaliação da RP, como indicador dos atributos físicos, houve uma melhor distinção dos tratamentos investigados. No sistema de tráfego controlado de máquinas é esperado o incremento na $\mathrm{RP}$ nos locais pré-determinados para receber o tráfego, evitando assim que ele ocorra de maneira aleatória dentro da área (TULLBERG et al., 2007).
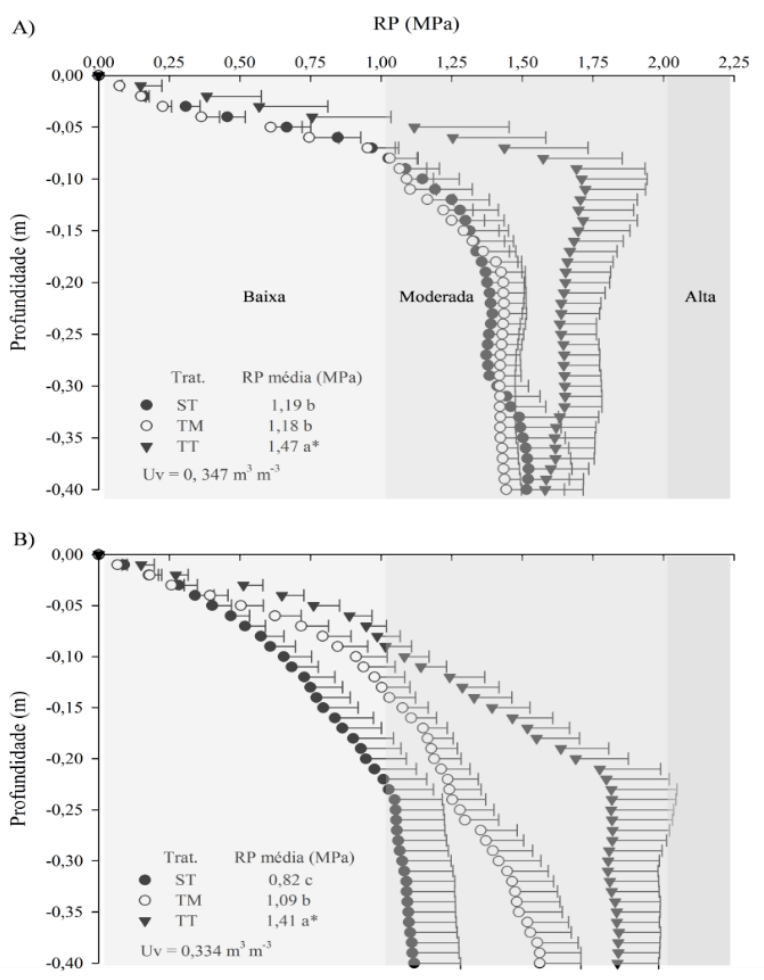

Figura 3 - Resistência a Penetração (RP) após a semeadura da soja (A) e no momento do pleno florescimento da cultura (B), classificada de acordo com Arshad et al. (1996). Onde: ST = Sem tráfego, TT $=$ Tráfego do trator-semeadora e TM $=$ Tráfego máximo. $\mathrm{Uv}_{\mathbf{v}}=$ umidade volumétrica do solo. *Médias seguidas de letras distintas diferem significativamente a nível de $5 \%$ de probabilidade pelo Teste de Tukey. Município de Céu Azul- PR.

Neste estudo observou-se que o incremento da RP ocorreu também em profundidade, com os maiores valores sendo observados em profundidade logo abaixo de $0,10 \mathrm{~m}$, na avaliação após a semeadura e em profundidades maiores que $0,20 \mathrm{~m}$, no pleno florescimento. Este aumento da RP em profundidade corrobora com o anteriormente reportado por Rosim et al. (2012) que observaram que os aumentos de RP aconteceram após o tráfego de máquinas sob diferentes quantidades de cobertura vegetal $\left(5,10,15 \mathrm{Mg} \mathrm{ha}^{-1}\right)$ em um Latossolo Vermelho, observando incremento da RP abaixo da camada de $0,10 \mathrm{~m}$, independentemente da quantidade de residuo mantido na superfície.

Utilizando avaliações em um transecto foi possível constatar o aumento da RP na linha de tráfego em ambos os tratamentos com trânsito de máquinas. $\mathrm{Na}$ figura $4 \mathrm{~A}$, observa-se que não ocorreram locais com elevada RP, em nem uma área a RP atingiu os limites propostos como limitante ao desenvolvimento radicular da cultura da soja. Esta ausência de limitação ao desenvolvimento radicular ocorreu pelo fato desta área ficar isenta de qualquer 


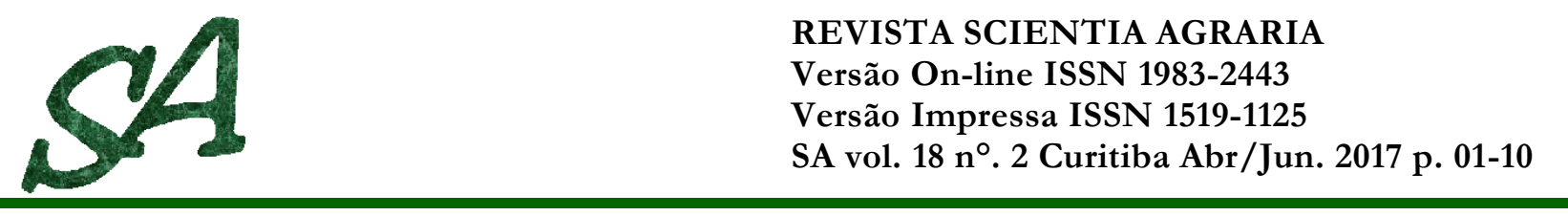

tipo de pressão no solo causada pelos pneus das máquinas agrícolas.

O tráfego do conjunto trator-semeadora (Figura 4 B) gerou, notadamente na linha de tráfego, um aumento da RP na profundidade de 0,15 a 0,40 $\mathrm{m}$. Por outro lado, verificou-se uma redução na RP na área adjacente a linha de semeadura, na profundidade 0 a $0,10 \mathrm{~m}$, ocasionado provavelmente pelo uso de sulcador na operação da semeadura. Na Figura 4 C é apresentado o tráfego acumulado do conjunto trator-semeadora e do pulverizador, e neste caso notou-se que o aumento da RP foi verificado apartir de $0,05 \mathrm{~m}$ atingindo toda a camada estudada. O incremento da RP apresentou uma maior área no tratamento TM do que no TT. Neste caso, a RP alcançou o limite crítico, embora com uma área de ocorrência localizada abaixo da linha de trafego. A medida que se afastou da linha de tráfego, verificou-se o decréscimo da RP. No tratamento TM observou-se que a área com baixa $\mathrm{RP}$ ficou restringida aos primeiros $0,05 \mathrm{~m}$, enquanto no TT esta camada com baixa RP atingiu os primeiros $0,15 \mathrm{~m}$.

De acordo com Botta et al. (2012) as pressões aplicadas sobre a superfície do solo são distribuídas ao longo do perfil, em função das tensões e das deformações, em maior ou menor escala, de acordo com as características físicas do solo. Neste sentido, o tráfego intenso transmitiu as pressões aplicadas para camadas mais profundas alcançando $0,40 \mathrm{~m}$ e com maior aleatoriedade, tanto no sentido horizontal como vertical, sendo que a existência de compactação subsuperficial é decorrente da carga total aplicada por eixo das máquinas e do histórico de tráfego anteriores na área (ALAKUKKU et al., 2003).

O aumento da RP na camada abaixo de 0,15 $\mathrm{m}$ devido ao tráfego de máquinas agrícolas também foi anteriormente reportado em um Argisolo Vermelho por Rosa et al. (2012). Neste estudo, embora não atingindo valores restritivos ao desenvolvimento do sistema radicular o aumento da RP foi acompanhando pelo aumento da densidade e redução da macroporosidade do solo, evidenciando aumento do nível de compactação após o tráfego de máquinas.

Ainda, é possível observar o efeito ocasionado pela presença do sulcador na semeadora durante o processo de semeadura, que possivelmente aliviou a compactação, favorecendo assim o desensevolvimento inicial da cultura. Nestas linhas de semeadura são encontrados os menores valores de RP em todos os tratamentos avaliados (Figura 4).

Os tratamentos com a presença de tráfego causaram o aumento da RP em profundidade, especialmente na linha de trânsito, e sua localização em profundidade maior que $0,15 \mathrm{~m}$ deve ser motivo de maior preocupação, visto que a redução ou eliminação da compactação no subsolo (profundidade $>0,20 \mathrm{~m}$ ) é mais difícil, demanda altos custos, bem como pode implicar na redução do aproveitamento de nutrientes e da água do solo (ALAKUKKU et al., 2003). Ainda, sua reversão por métodos biológicos como sistema radicular das culturas de grãos e atividade da fauna do solo é menos provável que nas camadas mais superficiais.
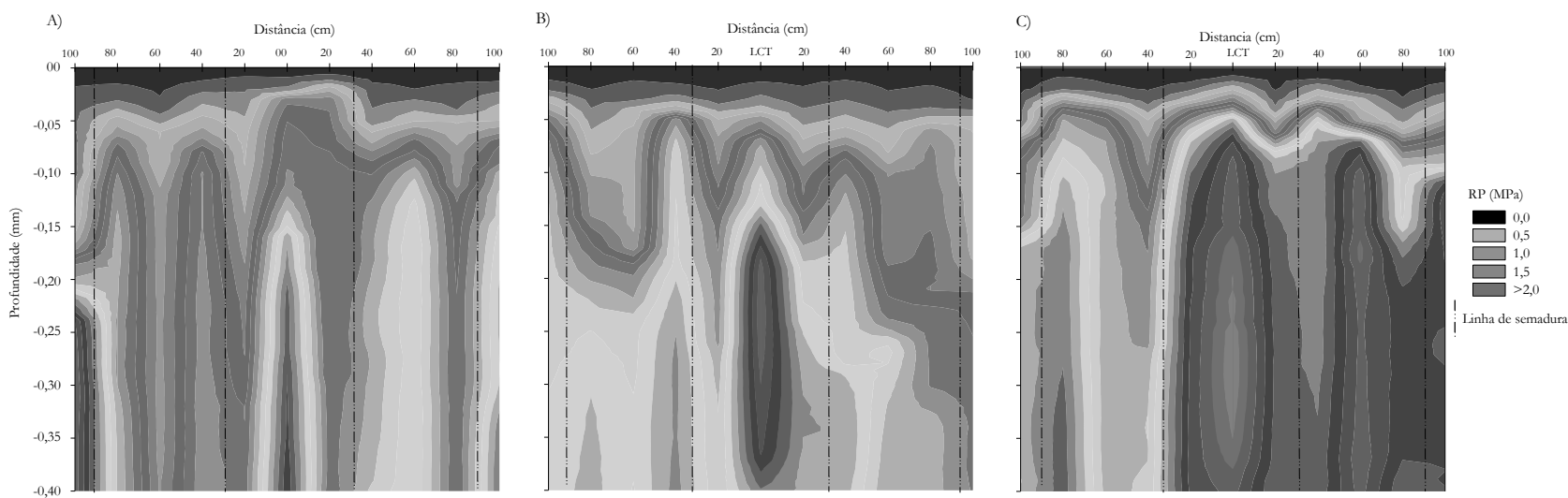

Figura 4 - Resistência a Penetração (RP) na área livre de tráfego (A), após o tráfego do conjunto trator-semeadora TT (B), após o tráfego acumulado do conjunto trator-semeadora mais pulverizador TM (C), logo após a semeadura da soja, espaçado equidistante em relação a linha de tráfego do trator e linhas de semeadura Céu Azul- PR. Onde: LCT = linha central de tráfego. Município de Céu Azul - PR. 


\section{Sistema radicular da cultura da soja}

$\mathrm{Na}$ camada superficial $(00-0,10 \mathrm{~m})$ não foi observado diferença significativa entre os tratamentos, porém o maior comprimento do sistema radicular foi registrado no TM, seguido pelo TT e ST (Figura 5). A semelhança no desenvolvimento radicular da soja entre os tratamentos era esperado uma vez que havia ausência de compactação do solo nesta camada (Figura 3 B). O ligeiro incremento no tratamento TM pode estar associado ao incremento da RP em profundidade, nesta situação a planta adapta-se reduzindo seu crescimento em profundidade e aumentando na camada superficial através do estímulo as raízes laterais em detrimento da raíz principal (FREDDI et al., 2009).

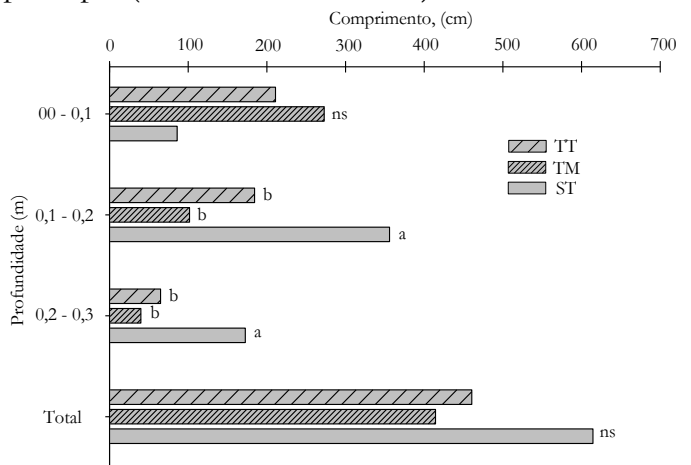

Figura 5 - Comprimento total das raízes da soja, no pleno florescimento, em diferentes camadas de solo após aplicação dos tratamentos, em cada profundidade avaliada. Onde: ST = Sem tráfego, TT $=$ Tráfego do trator-semeadora e TM $=$ Tráfego máximo. *Médias seguidas de letras distintas diferem significativamente a nível de $5 \%$ de probabilidade pelo teste de Tukey. Município de Céu Azul- PR.

Já na camada abaixo de 0,10 m o tratamento ST apresentou o maior comprimento de raiz entre os tratamentos investigados. $\mathrm{Na}$ camada adjacente (0,20-0,30 m), de modo análogo, o tratamento ST também apresentou maior comprimento de raízes em relação aos demais tratamentos. Estes resultados estão de acordo com a menor RP nestas camadas no tratamento ST em relação aos demais com ocorrência de tráfego das máquinas (TM e TT) (Figura 4 A e B).A maior concentração do sistema radicular da soja ocorreu até os $0,20 \mathrm{~m}$ sendo este efeito intensificado nos tratamentos com maior trânsito de máquinas, com 90 e 86\% das raízes ocorrendo nesta camada nos tratamentos TT e TM, respectivamente.

Estes resultados corroboram com Torres et al. (1993) que investigando o desenvolvimento do sistema radicular da soja em dois sistemas de preparo em um Latossolo, reportaram que apesar de atingir camadas de solo mais profundas, 80-90\% das raízes da soja se concentraram nos primeiros 0,20 $\mathrm{m}$ de solo. Por outro lado, Oliveira et al (2012) não encontraram diferença entre o comprimento total do sistema radicular da soja submetido a níveis de compactação em um em Latossolo Vermelho com teores de argila de $550 \mathrm{~g} \mathrm{~kg}^{-1}$. Já, neste estudo, no tratamento ST a concentração de raízes até os 0,20 $\mathrm{m}$ foi de $71 \%$, sugerindo que a ausência de trânsito proporcionou um maior aprofundamento do sistema radicular.

Neste estudo, nas duas camadas subsuperficiais os incrementos do comprimento do sistema radicular foram de 2555 e $132 \mathrm{~cm}$, nas camadas de $0.10-0.20 \mathrm{~m}$ e $0.20-0.30 \mathrm{~m}$, respectivamente, no tratamento ST em relação ao TM. O maior crescimento radicular em profundidade permite que a planta acesse maior volume de água em períodos de déficit hídrico e a nutrientes sujeitos a lixiviação, como nitrogênio, boro e enxofre, melhorando assim o seu aproveitamento pela cultura e reduzindo o impacto ambiental (MEDEIROS et al., 2005).

Produtividade da cultura da soja afetada pelo tráfego de máquinas agrícolas

A produtividade da cultura da soja não apresentou diferença estatística entre os tratamentos investigados, sendo a média geral do experimento de $4.010 \mathrm{~kg} \mathrm{ha}{ }^{-1}$ (Figura 6). O tratamento ST, com produtividade de $4.220 \mathrm{~kg} \mathrm{ha}^{-1}$, apresentou produção $20,7 \%$ maior que a média da produtividade da soja no estado do Paraná, no ano de 2012/2013 que foi de $3.344 \mathrm{~kg} \mathrm{ha}^{-1}$ (EMBRAPA, 2014).

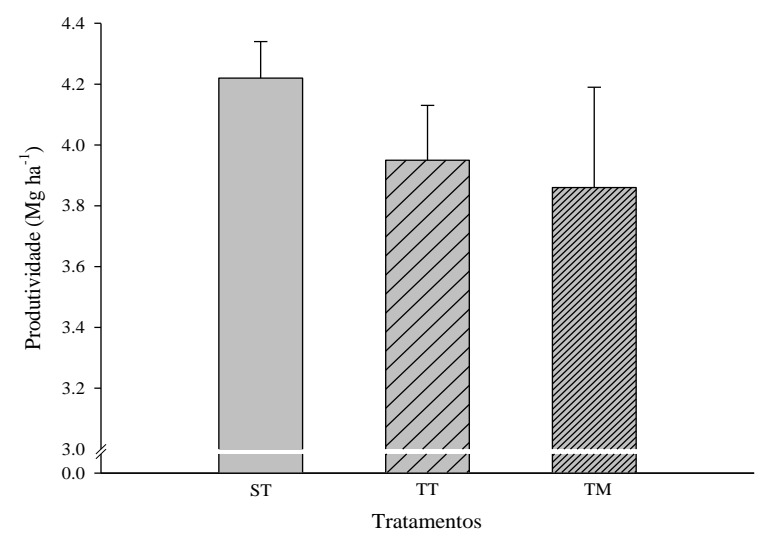

Figura 6 - Produtividade média da cultura da soja. ST $=$ Sem tráfego, TT $=$ Tráfego do tratorsemeadora e TM = Tráfego máximo. Município de Céu Azul- PR. 


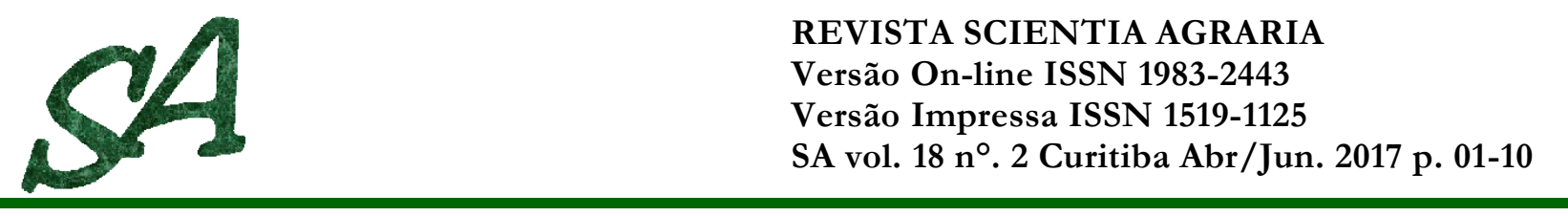

Este resultado de elevada produtividade de soja, independente do tratamento investigado, está coerente com a qualidade física do solo que não apresentou restrições ao desenvolvimento do sistema radicular em nenhum dos tratamentos. Anteriormente, Cardoso et al. (2006) em um trabalho realizado sobre um Latossolo concluíram que em um grau moderado de compactação induzido pelo tráfego de máquinas, associado a satisfatória disponibilidade hídrica às plantas não ocasionou decréscimo na produtividade da cultura da soja. Na safra investigada neste estudo, as condições climáticas foram consideradas favoráveis ao desenvolvimento da soja, fato suportado pela elevada produtividade obtida. A precipitação durante o ciclo da cultura foi de $640 \mathrm{~mm}$, sendo bem distribuída durante o ciclo, especialmente nas fases críticas.

Outro fator que deve ser considerado diz respeito às modificações realizadas na operação de semeadura para a execução do tráfego controlado, de modo que a linha de trânsito não é semeada e, portanto, não ocasiona efeito direto sobre as plantas. Porém, após o tráfego do pulverizador no tratamento TM, mesmo não apresentando diferença estatística em relação aos demais tratamentos observou-se a menor produtividade, com uma diferença entre o tratamento ST e o TM de $360 \mathrm{~kg}$ ha ${ }^{-1}$.

\section{CONCLUSÕES}

O tráfego controlado foi uma estratégia eficiente de confinar a compactação a linha de trânsito das máquinas agrícolas, promovendo o decréscimo da RP e favorencendo o crescimento radicular da soja nas camadas subsuperficiais na zona livre de trânsito.

Foi identificado o aumento da RP na linha central do tráfego na camada de 0,05-0,40 m nos tratamentos com elevado tráfego de máquinas.

O tráfego de máquinas ocasionou redução no comprimento do sistema radicular da cultura da soja nas camadas de solo de 0,10 - 0,20 m e 0,20 $0,30 \mathrm{~m}$ de profundidade e incremento na camada de $0,0-0,10 \mathrm{~m}$.

A produtividade de soja, nas condições do presente experimento de compactação moderada em um ano com precipitação elevada, não foi influenciada pelo tráfego controlado de máquinas agrícolas.

\section{AGRADECIMENTOS}

Os autores agradecem à Coordenação de Aperfeiçoamento de Pessoal de Nível Superior (Capes), pela concessão de bolsas de doutorado e de pós doutorado do primeiro autor à Agropecuária Tasca pela cedência da área e dos equipamentos envolvidos na pesquisa.

\section{REFERÊNCIAS BIBLIOGRÁFICAS}

ALAKUKKU, L.; WEISSKOPF, P.; CHAMEN, W. C. T.; TIJINK, F. G. J.; VAN DER LINDEN, J. P.; PIRES, S.; SOMMER, C.; SPOOR G. Prevention strategies for field trafficinduced subsoil compaction: A review Part 1. Machine/soil interactions. Soil Till Ressearch, v.73, p. 145160, 2003.

ALBA, P. J.; AMADO, T. J. C.; GIRARDELLO, V. C.; SCHOSSLER, D. S.; HORBE, T. A. N. Tráfego controlado em culturas de grãos no RS: Princípios, desafios e resultados preliminares. Revista Plantio Direto, v. 112, p. 40-47, 2011.

ARSHAD, M. A.; LOWERY, B.; GROSSMAN, B. Physical tests for monitoring soil quality. In: DORAN, J. W. \& JONES, A. J., Ed. Methods for assessing soil quality. Soil Science Society of America Journal, p. 123-141, 1996.

BENGOUGH, A. G.; BRANSBY, M. F.; HANS, J.; MCKENNA, S. J.; ROBERTS, T. J.; VALENTINE, T. A. Root responses to soil physical conditions; growth dynamics from field to cell. Journal of Experimental Botany, v. 57, p. 437-447, 2006.

BOCHTIS, D.D.; SØRENSEN, C. G.; GREEN, O.; MOSHOU, D.; OLESEN, J. Effect of controlled traffic in field efficiency. Biosystems Engineering, v. 106, p. 14-25, 2010.

BOTTA, G.F.; TOLON-BECERRA, A.; TOUM, M.; BRAVO-LASTRA, X.; RIVERO, D. Agricultural traffic: Motion resistance and soil compaction in relation to tractor design and different soil conditions. Soil Tillage Ressearch, v. 120, p. $92-98,2012$.

CARDOSO, E .G.; ZOTARELLI, L.; PICCININ, J. L.; TORRES, E.; SARAIVA, O. F.; GUIMARÃES, M. F. Sistema radicular da soja em função da compactação do solo no sistema de plantio direto. Pesquisa Agropecuaria Brasileira, v. 41, p. 493-501, 2006. 
CHAMEN, W. C. T.; ALAKUKKU, L.; PIRES, S.; SOMMER, C.; SPOOR, G.; TIJINK, F.; WEISSKOPF, P. Prevention strategies for field traffic-induced subsoil compaction: A review. Part 2. Equipment and field practices. Soil Tillage Ressearch. v. 73, p. 161-174, 2003.

CHAN, K. Y.; OATES, A.; SWAN, A. D.; HAYES, R. C.; DEAR, B.S.; PEOPLES, M. B. Agronomic consequences of tractor wheel compaction on a clay soil. Soil Tillage Ressearch, v. 89, p. 13-21, 2006.

CHEN, G.; WEIL, R. R. Penetration of cover crop roots thorugh compacted soils. Plant and Soil, v. 331, p. 31-43, 2010.

CRESTANA, S.; GUIMARÃES, M. F.; JORGE, L. A. C.; RALISCH, R.; TOZZI, C. L.; TORRENETO, A.; VAZ C. M. P. Avaliação da distribuição de raízes no solo auxiliada por processamento de imagens digitais. Revista Brasileira de Ciência do Solo, v. 18, p. 365-371, 1994.

EMPRESA BRASILEIRA DE PESQUISA AGROPECUÁRIA - EMBRAPA. Sistema brasileiro de classificação de solos. 3ª . ed. Brasília, DF: 2013.

EMPRESA BRASILEIRA DE PESQUISA AGROPECUÁRIA - EMBRAPA. - Soja em números. 2014 [acesso em 14 fev 2014] Disponível em: http://www.cnpso.embrapa.br/index.php

ETANA, A.; LARSBO, M.; KELLER, T.; ARVIDSSON, J.; SCHJØNNING, P.; FORKMAN, J.; JARVIS, N. Persistent subsoil compaction and its effects on preferential flow patterns in a loamy till soil. Geoderma, v. 192, p. 430436, 2013.

FER, W. R.; CANVINESS, E. C.; BURMOOD, D. T.; PENNINGTON, J. S.; Stage of development descriptions for soybeans, Glycine max (L.) Merrill. Crop Science, v. 11, :p. 929-931, 1971.

FREDDI, O. S.; CENTURION, J. F.; ALMEIRA, C. X. Compactação de um. Latossolo Vermelho de textura argilosa afetando o sistema radicular e a produtividade do milho. Revista Ceres, v. 56, p. 654665, 2009.

GASSEN, D. Tráfego controlado como alternativa para reduzir a compactação do solo. Revista Plantio Direto, v. 111, p.4-10, 2011.

KROULIK, M.; KVIZ, Z.; KUMBHALA, F.; HULA, J.; LOCH, T. Procedures of soil farming allowing reduction of compaction. Precision Agriculture, v. 12, p. 317-333, 2011.

MAZURANA, M.; FINK, J. R.; SILVEIRA, V. H.; LEVIEN, R.; ZULPO, L.; BREZOLIN, D. Propriedades físicas do solo e crescimento de raízes de milho em um argissolo vermelho sob tráfego controlado de máquinas. Revista Brasileira de Ciência do Solo, v. 37, p. 1185-1195, 2013.

MCHUG, A.D.; TULLBERG, J. N.; FREEBAM, D. M.; Controlled traffic farming restores soil structure. Soil Tillage Ressearch, v. 104, p.164:172, 2009.

MEDEIROS, R. D.; SOARES, A. A.; GUIMARÃES, R. M. Compactação do solo e manejo da água. I: efeitos sobre absorção de N, P, $\mathrm{K}$, massa seca de raízes e parte aérea de plantas de arroz. Ciência e Agrotecnologia, v. 29, p. 940-947, 2005.

QINGJIE W, H. A. O. C.; HONGWEN, L.; WENYING, L.; XIAOYAN, W.; MCHUNG, A. D.; JIN, H.; HUANWENG, G. Controlled traffic farming with no tillage for improved fallow water storage and crop yield on the Chinese Loess Plateau. Soil Tillage Ressearch, v. 104, p.192:197, 2009.

ROSA, D. P.; REICHERT, J. M.; MENTGES, M. I.; ROSA, V. T.; VIEIRA, D. A.; REINERT, D. J. Demanda de tração e propriedades físicas de um Argissolo em diferentes manejos e intensidades de tráfego. Pesquisa Agropecuaria Brasileira, v. 47, p. 118126. 2012.

ROSIN, D. C.; DE MARIA, I. C.; SILVA, R. L.; SILVA, A. P. Compactação de um Latossolo Vermelho Distroférrico com diferentes quantidades e manejos de palha em superfície. Bragantia, v. 71, p. 502-508, 2012.

SILVA, F. A. S.; AZEVEDO, C. A. Principal Components Analysis in the Software AssistatStatistical Attendance. In: Word Congress On Computers In Agriculture 7, Reno-NV-USA: American Society of Agricultural and Biological Engineers, 2009.

STEFANOSKI, D. C.; SANTOS, G. S.; MARCHÃO, R. L.; PETTTER, F. A.; PACHECO, L. P. Uso e manejo do solo e seus impactos sobre a qualidade física. Revista Brasileira de Engenharia Agricola e Ambiental. Campina Grande-PB, v.17, n.12, p.1301-309, 2013.

TORMENA, C. A.; ROLOFF, G.; SÁ, J. C. M. Propriedades físicas do solo sob plantio direto 
influenciadas por calagem, preparo inicial e tráfego. Revista Brasileira de Ciência do Solo. v. 2, p. 301-309, 1998

TORMENA, C. A.; ARAUJO, M. A.; FIDALSKI, J.; COSTA, J. M. Variação temporal do intervalo hídrico ótimo de um latossolo vermelho distroférrico sob sistemas de plantio direto. Revista Brasileira de Ciência do Solo. v. 31, p.211-219, 2007.

TORRES, E.; SARAIVA, O. F.; GALERANI, P. R. Manejo do solo para a cultura da soja. Londrina: Embrapa Soja, 1993. 71p. (Embrapa Soja. Circular técnica, 12).

TREIN, C. R.; MACHADO, A. P.; LEVIEN R. Compactação do solo por rodados, podemos evitála. Revista Plantio Direto. v. 114, p. 23-34, 2009.

TULLBERG, J. N.; YULI, D. F.; MCGARRY D. Controlled traffic farming-From research to adoption in Australia. Soil Tillage Research, v. 97, p. 272-281, 2007. 